Journal of Patient-Centered coAdvocateAuroraHealth

Research and Reviews

Volume 5

Issue 1 - Health Disparities and Inequities: Part

Article 6 II

$1-30-2018$

\title{
Community Health, Advocacy, and Managing Populations (CHAMP) Longitudinal Residency Education and Evaluation
}

Kjersti E. Knox

Will Lehmann

Joseph Vogelgesang

Deborah Simpson

Follow this and additional works at: https://aah.org/jpcrr

Part of the Community Health and Preventive Medicine Commons, Family Medicine Commons, Medical Education Commons, Medical Humanities Commons, and the Primary Care Commons

\section{Recommended Citation}

Knox KE, Lehmann W, Vogelgesang J, Simpson D. Community Health, Advocacy, and Managing Populations (CHAMP) longitudinal residency education and evaluation. J Patient Cent Res Rev. 2018;5:45-54. doi: 10.17294/2330-0698.1580

Published quarterly by Midwest-based health system Advocate Aurora Health and indexed in PubMed Central, the Journal of Patient-Centered Research and Reviews (JPCRR) is an open access, peer-reviewed medical journal focused on disseminating scholarly works devoted to improving patient-centered care practices, health outcomes, and the patient experience. 


\title{
Community Health, Advocacy, and Managing Populations (CHAMP) Longitudinal Residency Education and Evaluation
}

\author{
Kjersti E. Knox, MD, ${ }^{1,2}$ Will Lehmann, MD, MPH, ${ }^{1,2}$ Joseph Vogelgesang, DO, ${ }^{1}$ Deborah Simpson, $\mathrm{PhD}^{1,2}$ \\ ${ }^{1}$ Family Medicine, Aurora Health Care, Milwaukee, WI; ${ }^{2}$ Department of Family Medicine and Community Health, \\ University of Wisconsin School of Medicine and Public Health, Madison, WI
}
Purpose Longitudinal education initiatives designed to prepare residents to address health disparities and social determinants of health (SDH) are needed. This report addresses this gap by describing a family medicine residency's Community Health, Advocacy, and Managing Populations (CHAMP) curriculum and its evaluation by learners, faculty, and community partners. The CHAMP longitudinal curriculum is explicitly designed to prepare residents to address health disparities and SDH. We report early outcomes, including community partner feedback, of this innovative curriculum.

Methods Data were obtained through standardized rotation evaluations, thematic analysis of structured group and individual interviews, and aggregated competency milestone data. Kirkpatrick's four-level model to evaluate effectiveness of training was used to frame design and analysis of learner, faculty, and community partner evaluations.

Results Twenty residents have completed the year-one curriculum, 8 residents the year-two curriculum, and 8 residents the year-two and year-three elective. Community partners, residents, faculty, and leadership all were satisfied with the curriculum, particularly regarding relationship building and mentorship. Overall satisfaction with the rotation, quantitatively and qualitatively, was positive. Competency milestone ratings improved within each year of training: first-year residents by 0.6 (3.0 for 2015-2016 and 3.6 for 20162017 ) and second-year residents by 0.1 (5.2 vs 5.3).

Conclusions The CHAMP curriculum uniquely a) spans all three years of residency; b) combines block mandatory rotations with a longitudinal elective experience; and c) integrates community health, advocacy, and managing populations to meet accreditation requirements and prepare residents to address health disparities and SDH. (J Patient Cent Res Rev. 2018;5:45-54.)

Keywords community health; residency, medical education; social determinants of health; population health; longitudinal curriculum

$\mathrm{T}$ he 2008 triple aim for health care ${ }^{1}$ emphasizes quality of care for patients and populations while reducing cost and reframes how we think about health. The U.S. Institute of Medicine (now named Health and Medicine Division) subsequently called on medicine and public health to improve collaborations ${ }^{2}$ by using an ecological model of health,

Correspondence: Kjersti E. Knox, MD,

Aurora Sinai Family Care Center, 1020 N. 12th Street, 2nd Floor, Milwaukee, WI, 53233, T: +1-414-219-5219;

Email: kjersti.knox@aurora.org which emphasizes nonmedical determinants of health including education, economics, work conditions, and public policy, ${ }^{3}$ also known as social and environmental determinants of health. ${ }^{4}$

The World Health Organization defines social determinants of health (SDH) as "... the conditions in which people are born, grow, live, work and age. These circumstances are shaped by the distribution of money, power and resources at global, national and local levels. Social determinants of health are mostly responsible for health inequities — the unfair and 
avoidable differences in health status seen within and between countries." ${ }^{5}$ In contrast, health equity is the concept that all people and communities "have a fair and just opportunity" to reach the highest standards of health, regardless of their zip code. ${ }^{4}$ It has been acknowledged that zip codes impact health outcomes more than genetic codes. ${ }^{6,7}$

Training a socially responsive primary care workforce to provide patient-centered care that incorporates community partners and addresses the health needs of our communities is an Institute of Medicine goal. ${ }^{8}$ The skills to identify and address SDH are critical for patient care and the modern practice of medicine and population management, an ever-increasing component of primary care physicians' clinical practice.

A high-yield approach to meet the Institute of Medicine's goal lies in how we train and nurture future health care professionals. However, studies with data that delineate specific strategies to reach this goal are limited. Graduate medical education (GME) formally approaches the goal through Accreditation Council for Graduate Medical Education (ACGME) requirements, including competency in systems-based practice. ${ }^{9}$ However, program-specific strategies vary and recent GME-level studies reveal that actual and perceived knowledge among residents about topics relating to underserved populations is low, highlighting the need to improve resident education to reduce disparities. ${ }^{10}$

Research has shown that trainees who have the firsthand experience of caring for underserved populations during residency are more likely to go on to practice in underserved settings after residency. ${ }^{11}$ Early evidence also suggests that offering experiential longitudinal curricula in community health with particular attention to underserved communities and addressing health disparities through community health, advocacy, and attention to SDH can provide budding physicians with the competencies to fulfill roles in advocacy, research, and policy-making. ${ }^{12,13}$

Current attempts to design GME curricula typically use a focused block experience (eg, 2 weeks or 1 month) during only 1 year of residency despite the evidence that longitudinal strategies are most effective. ${ }^{12,13}$ Unpublished early reports of longitudinal
SDH curricula that highlight competency progression by year of training are emerging through conference abstracts and/or informal sharing on web-based educational portals. Published reports of GME programs explicitly designed to prepare residents to address health disparities and SDH are needed. ${ }^{14}$

This report describes the Community Health, Advocacy, and Managing Populations (CHAMP) family medicine residency curriculum at Aurora Health Care (Milwaukee, WI) and its evaluation by learners and community partners to address the gap in GME literature. This novel SDH curriculum a) spans all 3 years of residency; b) combines block mandatory rotations with a longitudinal elective experience; and c) integrates community health, advocacy, and managing populations.

\section{CHAMP PROGRAM LEADERSHIP}

The CHAMP curriculum is sponsored by the Aurora Family Medicine Residency Program in Milwaukee, Wisconsin. Two residency program faculty serve as CHAMP directors with full support from program leaders and the faculty as a whole. Half of the program's faculty (9) serve as mentors for the year-one block rotation, and all faculty (18) serve as mentors for the year-two block rotation. Faculty represent a spectrum of experience in community health, health equity, and clinical practice patient populations. Residents and faculty care for patients at 5 clinics in the Milwaukee metropolitan area, each serving a unique patient population. The city of Milwaukee is a community of 600,000 people, $28.7 \%$ of whom live in poverty. ${ }^{15}$

\section{CHAMP CURRICULUM STRUCTURE}

CHAMP is a unique longitudinal curriculum for family medicine residents designed to integrate tools and skill building in community health, population health and management, advocacy, and health disparities into clinical practice. Drawing on selected elements from published programs, ${ }^{13,16-19}$ CHAMP longitudinal curriculum incorporates community partnerships, population analysis, and specialty clinical experiences to teach residents to identify and address SDH and health disparities in our community and clinics. CHAMP emphasizes identification of SDH and their downstream effects on health, and teaches residents to engage community members, leverage population 
health data, and build and lead interdisciplinary teams to address health disparities consistent with ACGME Family Medicine community and public health milestones. ${ }^{20}$

The CHAMP curriculum consists of four components: 1) a focus on core principles of community health and SDH during the year-one orientation block; 2) a community health block rotation in year one; 3 ) a population health management block rotation in year two; and 4) an elective Lead For Health (L4H) longitudinal community and population health engagement track spanning years two and three.
Category themes of advocacy, health disparities and $\mathrm{SDH}$, mentorship, team building, and project sharing to improve patient care are integrated throughout all aspects of the curriculum (Table 1).

\section{Component \#1: Core Principles of Community Health}

During resident orientation in year one, residents spend 10 hours discussing and practicing the core principles of community health and population management. Residents partake in an asset-based community development community-mapping exercise, ${ }^{21}$ which they present to their colleagues. They also learn and

Table 1. Community Health, Advocacy, and Managing Populations (CHAMP) Longitudinal Curriculum Overview by Training Year

\begin{tabular}{|c|c|c|c|c|c|c|c|c|c|c|}
\hline \multirow[b]{2}{*}{ Longitudinal curriculum structure and components $\downarrow$} & \multicolumn{3}{|c|}{ Year in training } & \multicolumn{5}{|c|}{ Curriculum concepts } & \multicolumn{2}{|c|}{ Methods } \\
\hline & 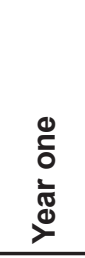 & 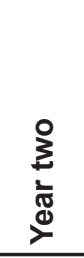 & 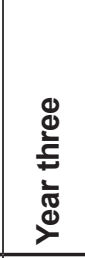 & 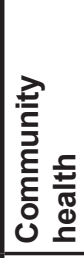 & 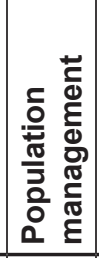 & 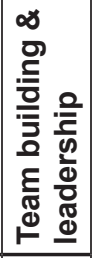 & 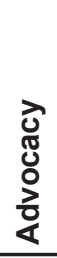 & 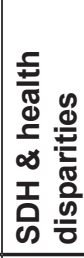 & 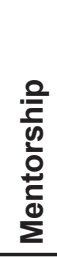 & 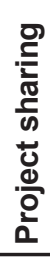 \\
\hline $\begin{array}{l}\text { Resident orientation: principles of community health } \\
\text { • Core principles of SDH } \\
\text { • Asset-based community development ("windshield } \\
\text { survey") } \\
\text { • Eco-mapping }\end{array}$ & $10 \mathrm{~h}$ & & & $\mathrm{x}$ & $\mathrm{x}$ & $\mathrm{x}$ & $\mathrm{x}$ & $\mathrm{x}$ & $\mathrm{X}$ & $\mathrm{X}$ \\
\hline $\begin{array}{l}\text { CHAMP 1: community health } \\
\text { - Partner organization visits } \\
\text { - Clinic: continuity, group visits, refugee clinic } \\
\text { - Advocacy project 1: policy change or community } \\
\text { education (employing narrative) } \\
\text { - Integrative medicine in residency modules }\end{array}$ & $1 \mathrm{mo}$ & & & $x$ & & $x$ & $x$ & $x$ & $\mathrm{x}$ & $x$ \\
\hline $\begin{array}{l}\text { CHAMP 2: managing populations } \\
\text { - Population management } \\
\text { - Clinic: continuity, group visits, refugee clinic } \\
\text { - Advocacy project 2: clinical practice change } \\
\text { (employing mini-PDSA cycle) } \\
\text { - Nursing home and home visits }\end{array}$ & & $1 \mathrm{mo}$ & & & $x$ & $x$ & $x$ & $x$ & $\mathrm{x}$ & $x$ \\
\hline $\begin{array}{l}\text { Longitudinal elective: Lead For Health } \\
\text { - Project development and implementation: partner } \\
\text { with clinic or community organization to address } \\
\text { population/public health need } \\
\text { - Specialized continuity clinic experience: free clinic; } \\
\text { FQHC; IHC; integrative medicine }\end{array}$ & & $48 \mathrm{~h}$ & $80 \mathrm{~h}$ & $x$ & $x$ & $\mathrm{x}$ & $x$ & $x$ & $x$ & $x$ \\
\hline
\end{tabular}

FQHC, federally qualified health center; IHC, Indian Health Center; PDSA, Plan, Do, Study, Act; SDH, social determinants of health. 
practice ecomapping ${ }^{22}$ to identify the role of SDH on patient health. Discussion of the expanded $\mathrm{SDH},{ }^{23}$ their relationship to health outcomes in Milwaukee as seen in the Milwaukee Health Report, ${ }^{7}$ and the role of physicians to advocate for change ${ }^{24}$ are explored.

\section{Component \#2: Community Health Block Rotation}

The first-year block rotation is 1 month long and focuses on community health experiences during which residents engage multiple contexts to identify and address health disparities and SDH. Residents visit and partner with the local Visiting Nurse Association; the public health department's sexually transmitted diseases, tuberculosis, and lead programs; a free clinic; a community-based integrative health program (CORE/ El Centro); a homeless shelter (Salvation Army); and a children's center (Penfield Children's Center). They facilitate refugee clinic visits and group visits in diabetes and weight loss, which provide focused exposure to direct influences of SDH on health and techniques of approaching them in these specialized settings. Multiple elective community experiences, such as visiting a domestic violence shelter, local Women, Infants, and Children (WIC) program office, and urban farm, also are offered to allow residents to tailor the CHAMP year-one block experience to their specific interests and patient population.

Half of rotation block time is spent caring for patients in their continuity clinic. Residents also learn to employ personal narrative combined with data to advocate for policy change or community education. Target audiences include clinical colleagues, system leaders, journals, newspapers, legislators (city, state, or national), and other venues as appropriate. All residents complete elements of the core-required Integrative Medicine in Residency curriculum, which activates personal health advocacy.

\section{Component \#3: Population Health Management Block Rotation}

The second-year block rotation is 1 month long and provides all year-two residents with opportunities to deepen their knowledge of community and population health and management in Milwaukee. Residents describe and manage their personal clinic patient population, improve clinical operations and efficiency for their patient population with use of care management and patient service and quality data, and develop skills to integrate community health, advocacy, and population management into their careers as primary care physicians.

Half of rotation block time is spent caring for patients in their continuity clinic. Residents partner with health systems informatics teams to pull patient-panel data, such as zip code of residence, and identify an area of need for their patient population and continuity clinic experience. Residents are encouraged to analyze data through an $\mathrm{SDH} /$ health equity lens, such as identifying root causes of communication barriers to assist patient completion of physician referrals. Residents then design, implement, and evaluate a clinical advocacy project using a mini-PDSA (Plan, Do, Study, Act) cycle.

Year-two residents may build on their year-one CHAMP advocacy project or $\mathrm{L} 4 \mathrm{H}$ project to design their year-two advocacy project. This affords residents an opportunity, if appropriate, to combine quality improvement, advocacy, and/or their scholarly project for improvement in population health and clinical quality to address health disparities and meet ACGME requirements. Quality improvement efforts typically emphasize change within the residents' personal clinic but often transfer to their colleagues and clinic as a whole. Year-two residents again direct refugee clinic as well as group diabetes and weight loss visits in addition to conducting home visits and nursing home visits.

\section{Component \#4: L4H Longitudinal Elective}

The L4H elective incorporates both community health and population management to provide a subset of residents with a greater depth of experience in project development and implementation in collaboration with a defined population to address a population or community health need. Residents are selected during the spring of year one of residency via an application process that factors in short essays, project design, and overall performance within the residency. Selected residents commit to join $\mathrm{L} 4 \mathrm{H}$ for their final 2 years of residency, with roughly 48 hours during year two and 80 hours during year three dedicated to the elective.

These residents are expected to devote at least 2 halfdays per non-call month to develop a scholarly project related to community health while maintaining standard 
continuity clinic, rotation, and program requirements. Projects range from group visit development to partnering with an Indian Health Center (IHC) to teach health education classes and increase access to medical care. Residents also commit to spend 4 hours each week in a unique clinical environment separate from their home continuity clinic, such as a free clinic, federally qualified health center, IHC clinic, or integrative medicine clinic. Some clinic sites qualify for ACGME continuity clinic experience.

Advocacy, identification and addressing of health disparities and SDH, mentorship, team building, leadership, and project sharing are central components to all parts of the CHAMP curriculum. Residents complete their self-selected advocacy projects with faculty mentorship during each phase of the CHAMP curriculum.

\section{EVALUATION METHODS}

Evaluation of the CHAMP curriculum uses the fourlevel Kirkpatrick Model to determine the effectiveness of training. ${ }^{25}$ Current evaluation efforts focus on levels 1-3 (reaction, learning, and behavior) and short-term level 4 (results). Obtaining long-term level 4 results from graduates is planned.

To obtain data at levels 1-3 and level 4 (short-term), multiple sources of data are used: 1) the program's standard end-of-block-rotation evaluation using a GME online management system; 2) structured group debriefs with year-one residents, year-two residents, L4H residents, faculty, and program leadership; 3) structured interviews with individual community partners; 4) resident advocacy and PDSA projects; and 5) aggregated ACGME milestone data by training year.

Block rotation evaluations used the residency's uniform end-of-rotation questionnaire available to a resident following completion of the block and collected throughout the academic year. Evaluations solicit feedback using 5-point Likert scales with room for written comments. The same evaluation form is used for all residency rotations.

The structured group debriefs were designed consistent with a grounded-theory approach to qualitative evaluation $^{26}$ in order to obtain participant, program leader, and community perspectives on CHAMP.
Resident debrief participants were matched to their level of training (reaction and learning), what they have incorporated into their role as a physician, what has impacted their daily practice as a clinician (behavior), and impacts on residency program/recruitment and project impacts on health care system/community (short-term results). Year-one and year-two resident debriefs were conducted during the program's annual meeting and facilitated by 1 resident and 1 faculty member, who followed a scripted discussion outline with open-ended questions. L4H, faculty, and program leadership debriefs were collected by this report's first author during scheduled meetings.

Community partner interviews explored respondents' perceptions regarding the ways in which the CHAMP experience matched their expectations, strengths, opportunities to improve (reaction, resident learning, behavior), and the value of participating in the CHAMP program (results). The first author conducted all community partner interviews via phone following a standardized open-ended interview structure. All debriefs were conducted in May and June 2017. To allow a common framing of narrative results across participants, narrative responses were independently reviewed by three faculty authors and coded by Kirkpatrick level consistent with the utility, stakeholder perspective, and feasibility standards for using narrative data for evaluation (vs research). ${ }^{27}$ Within each level, each faculty coder then identified categories by respondent group consistent with an inductive qualitative content analysis approach. ${ }^{28}$ Faculty then met to review each coder's emergent categories and finalize categories through consensus.

The local institutional review board deemed these evaluations to be not-human-subjects research.

\section{RESULTS}

The CHAMP curriculum was phased in beginning in 2013 with full implementation in 2015. To date, 20 residents have completed the year-one curriculum, 8 residents have completed the year-two curriculum, and 8 residents have completed the 2-year L4H elective. Faculty participation has remained constant, with 50\% serving as mentors for the year-one rotation and all faculty available to serve as mentors for the year-two rotation. Eight regularly scheduled community partners 
contribute to the CHAMP block curricula, with more than 10 other elective partners intermittently scheduled.

\section{Block Rotation Quantitative Evaluations}

Resident evaluation of CHAMP curriculum elements revealed 16 residents completed quantitative evaluation of the year-one CHAMP rotation since its start. Residents assessed the CHAMP year-one block rotation expectations, teaching structure, and skill development using a 5-point scale (Table 2). Quantitative evaluations of the year-two CHAMP rotation were not available at writing.

\section{Structured Group Debriefs and Community Interviews by Kirkpatrick Level}

Evaluation categories from the narrative data by learners, faculty, program leadership, administrator, and community partners, along with the percentage of data sources responding in that category, are presented by Kirkpatrick level in Table 3.

Reaction: Logistics associated with the CHAMP curriculum was the only common category theme to emerge in all groups. Respondents focused on clarity (or lack thereof) specific to project requirements, including expectations of residents and mentors, scope, and timing. Residents appreciated direct interaction with the community outside the clinics and hospitals as well as learning patient stories. The mentorship relationship between residents and faculty as well as the advocacy projects were valued by both faculty and residents, and faculty and residency leadership specifically requested guidance for mentorship responsibilities. Community partners identified opportunities to grow the curriculum, including increasing resident time with community partners, providing feedback to community partners from the residents, and improving communication about the curriculum outside of the residency. Program leaders, faculty, and residents all recognized potential for the CHAMP curriculum to shape the residency's external identity and reputation. However, there was lack of agreement as to whether this identity was recognized internally. Community partners saw establishing the relationship with residents as a priority to be able to increase translational learning for residents.

Learning: Community partners commented specifically on residents learning about health equity and SDH and doing so within a structure that promotes reflection and prevents feeling overwhelmed. The community partners emphasized the need to provide opportunities for residents to process or debrief their community experiences to promote deeper learning and suggested this could be done in a team with community partners.

Behavior: Residents, faculty, and program leadership noted direct implementation of community and population management resources learned or developed by residents into patient care by both residents and faculty. Community partners emphasized the importance of this Kirkpatrick training level, commenting specifically on this as a key moment in training to influence residents' practice following residency.

Results: Community partners reported key impacts both individual and for their organizations. Respondents, as well as the curriculum administrator, indicated (re)finding and rekindling their meaning and purpose

Table 2. CHAMP Year-One Block Rotation Quantitative Assessment

\begin{tabular}{|c|c|c|}
\hline Item & Rating scale & Score (1-5) \\
\hline Rotation expectations & $\begin{array}{l}1=\text { Not discussed }, \text { unclear } \\
3=\text { Implied but not discussed } \\
5=\text { Clear what I should learn and what the expectations were }\end{array}$ & 4.4 \\
\hline Teaching structure & $\begin{array}{l}1=\text { Disorganized }, \text { no dedicated time } \\
3=\text { Some attempts to teach } \\
5=\text { Thorough and consistent teaching efforts }\end{array}$ & 4.1 \\
\hline Skill development & $\begin{array}{l}1=\text { No opportunities to practice } \\
3=\text { Some opportunities to practice skills } \\
5=\text { Many opportunities to practice skills }\end{array}$ & 3.8 \\
\hline
\end{tabular}




\begin{tabular}{|c|c|c|c|c|c|c|c|c|c|}
\hline \multirow[b]{2}{*}{ Kirkpatrick levels and categories $\downarrow$} & \multirow[b]{2}{*}{$\frac{\frac{*}{\bar{N}}}{\frac{\bar{\pi}}{0}}$} & \multicolumn{8}{|c|}{ Data sources } \\
\hline & & 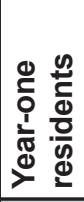 & 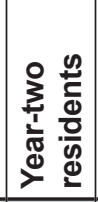 & 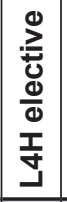 & 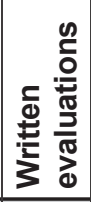 & 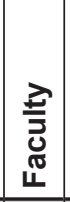 & 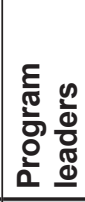 & 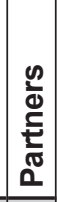 & 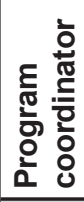 \\
\hline \multicolumn{10}{|l|}{ Reaction, satisfaction } \\
\hline $\begin{array}{l}\text { 1. Clarity of expectations/roles } \\
\text { - Clarity of project requirements, expectations, scope, timing } \\
\text { - Clarity of mentor role, responsibilities }\end{array}$ & $100 \%$ & $x$ & $x$ & $x$ & $x$ & $\begin{array}{l}X \\
X\end{array}$ & $\begin{array}{l}x \\
x\end{array}$ & $x$ & $x$ \\
\hline $\begin{array}{l}\text { 2. Relationship and partnerships } \\
\text { - Value partnership - organization and trainee interactions/experiences } \\
\text { - Value an established relationship between residents, partners } \\
\text { - Value opportunity to hear or experience patient stories } \\
\text { - Desire increased time together - residents and partner organizations } \\
\text { - Value faculty mentorship relationship }\end{array}$ & $100 \%$ & $\begin{array}{l}X \\
X \\
X\end{array}$ & $x$ & $\begin{array}{l}x \\
X \\
x \\
X \\
X\end{array}$ & $x$ & $x$ & $x$ & $\begin{array}{l}x \\
x \\
x \\
x\end{array}$ & $x$ \\
\hline $\begin{array}{l}\text { 3. Advocacy project } \\
\text { - Value advocacy and PDSA projects } \\
\text { - Challenge of focusing advocacy projects } \\
\text { - Desire advocacy project accessibility/improved dissemination }\end{array}$ & $68 \%$ & & $\begin{array}{l}x \\
x\end{array}$ & $\begin{array}{l}X \\
X \\
X\end{array}$ & $x$ & $\begin{array}{l}x \\
X \\
X\end{array}$ & $\begin{array}{l}X \\
X \\
X\end{array}$ & & \\
\hline $\begin{array}{l}\text { 4. Identity } \\
\text { - Provides program identity } \\
\text { - Improve external communication of identity - increase impact on } \\
\text { resident recruitment }\end{array}$ & $50 \%$ & $\begin{array}{l}x \\
x\end{array}$ & $\begin{array}{l}X \\
X\end{array}$ & & & & $\begin{array}{l}X \\
x\end{array}$ & & $\begin{array}{l}X \\
X\end{array}$ \\
\hline \multicolumn{10}{|l|}{ Learning } \\
\hline $\begin{array}{l}\text { 1. What is learned } \\
\text { - Residents learn health equity and SDH } \\
\text { - Residents learn complexity without becoming overwhelmed }\end{array}$ & $13 \%$ & & & & & & & $\begin{array}{l}x \\
X\end{array}$ & \\
\hline $\begin{array}{l}\text { 2. Strategies to increase learning } \\
\text { - Desire feedback on ROI from residents } \\
\text { - Desire setting to help residents reflect/process experience }\end{array}$ & $13 \%$ & & & & & & & $\begin{array}{l}x \\
x\end{array}$ & \\
\hline \multicolumn{10}{|l|}{ Application to practice/behavior } \\
\hline 1. Prepare for future of health care & $13 \%$ & & & & & & & $x$ & \\
\hline $\begin{array}{l}\text { 2. Integrate partner organizations and/or population management } \\
\text { resources in care }\end{array}$ & $87 \%$ & $x$ & $x$ & $x$ & $x$ & $x$ & $x$ & & \\
\hline \multicolumn{10}{|l|}{ Outcomes/results } \\
\hline 1. Find meaning and purpose & $38 \%$ & & & $x$ & & & & $x$ & $x$ \\
\hline 2. Add value to partner organizations & $25 \%$ & & & $x$ & & & & $x$ & \\
\hline 3. Inspire continued partnership & $25 \%$ & & & $x$ & & & & $x$ & \\
\hline
\end{tabular}

${ }^{*}$ Overall = percentage of data sources by category.

L4H, Lead For Health; PDSA, Plan, Do, Study, Act; ROI, return on investment; SDH, social determinants of health.

through teaching residents. They indicated that the residents' presence brought value to their organization in unique skills and knowledge and motivated their team to enhance their performance. Community partners also highlighted the value of the relationships between community partners and the residency program faculty and residents that emerged from CHAMP. Residents and faculty did not explicitly address this element. One community organization felt that exposure to their organization during the year-one CHAMP rotation 
led residents to choose the $\mathrm{L} 4 \mathrm{H}$ elective and continue clinical care with their organization.

Year-one residents tended to express that they liked the rotation (reaction), whereas year-two residents and L4H residents more frequently expressed what they learned and gave examples of how they transferred that knowledge to practice (learning and behavior). Block rotation residents did not comment on short- or longterm results.

\section{Resident Advocacy and PDSA Projects}

Faculty noted changes in resident clinical practice based on the advocacy projects and changes in their own clinical practice. Working with residents to scope a feasible project within the available timeframe was a key success feature. Leadership identified that with further expansion the CHAMP advocacy project could regularly fulfill ACGME quality improvement requirements (eg, multiple PDSA cycles). The need for a lasting common platform to share advocacy projects was identified.

\section{ACGME Milestone Data}

Milestone data was used for the 2015-2016 and 20162017 academic years (July-June), as it overlapped with the full implementation in 2015-2016. 2015-2016 mean ratings using ACGME's "Systems-Based Practice Milestone 3: Advocates for Individual and Community Health" demonstrated a progressive improvement each year of the program both within and between trainee levels. Competency milestone ratings improved within each year of training: first-year residents by 0.6 (3.0 for 2015-2016 and 3.6 for 2016-2017) and second-year residents by 0.1 (5.2 vs 5.3). In 2015-2016, faculty assessed first-year residents on average as 3.0 and second-year residents at 5.2 using 9-point scale from novice (1) to expert (9). Ratings improved for 20162017 academic year, with first-year residents at 3.7 and second-year residents at 5.3.

\section{DISCUSSION}

The Institute of Medicine has called for physician training to include SDH and has specifically identified the need for future primary care physicians to work within a patient-centered population management practice framework. Sustained practice and refinement of skills are crucial for establishing long-term practice patterns, making residency training a vital component in developing a primary care workforce that recognizes and addresses health disparities. ${ }^{8}$ CHAMP is an innovative curriculum designed to respond to this need through collaboration with community and clinical partners to train family physician residents to address health disparities and improve health equity.

While many residency programs have community health curricula, the scope and structures vary significantly. ${ }^{14}$ CHAMP is unique in its longitudinal structure spanning all 3 years of family medicine residency, its unique combination of community health, advocacy, and managing populations, and the combination of experiential learning (year one) and translational activities (year two) with a uniting category theme of advocacy throughout. As the first reported description and multisource evaluation of a longitudinal residency curriculum, our evaluation approach, like our curriculum, incorporates perspectives from our community partners.

Consistent with our CHAMP curriculum design, the evaluation found different degrees of recognition of behavior change between faculty and $\mathrm{L} 4 \mathrm{H}$ residents and early learners. Additionally, the competency progression observed over time for Systems-Based Practice Milestone 3 is consistent with the developmental progression built into the CHAMP curriculum. Learner responses by training year followed the progression in the Kirkpatrick Model for evaluating training. While year-one and yeartwo residents frequently expressed value and learning from the curriculum (Kirkpatrick levels 1-2), they rarely recognized translation/application of skills into their practice (Kirkpatrick level 3). In contrast, L4H residents and faculty/leadership recognized behavior change in their own and resident practice. Future evaluation will determine if this progression is associated with enhanced program communication (a category theme commented on by all interviewed) or if increased experience and clinical time is necessary to recognize opportunities for transfer to practice. We suspect that the addition of formal, intentional processing and reflection, suggested by our community partners, will be incorporated to support residents' transfer of learning to practice, consistent with the Yoder framework of service learning. ${ }^{29}$

Although program leadership identified the CHAMP curriculum as central to the residency's identity, this 
was not reflected in learner responses. Some learners reported that the CHAMP curriculum "could" increase recruitment of high-quality candidates, while others felt that this curriculum would not differentiate our program as all family medicine residencies would have a rigorous community health and advocacy education experience. This discrepancy in perception affirms what Kaprielian et al found in developing their population health competency map ${ }^{16}$ and suggests that clearly outlining the longitudinal and progressive CHAMP curricular components will increase understanding of CHAMP's scope, foundation, and strategic priority within the residency (in alignment with program pillars of advocacy and caring for underserved populations) and ease communication with learners.

Following data analysis, several CHAMP curriculum enhancements were identified. Immediate changes have already been implemented, including regular dissemination of advocacy projects as part of our monthly resident-faculty meetings and on the residency's home page. Long-term structured reflection exercises for residents to process their experiences, pathways for clear feedback to community partners, and improved communication about the curriculum outside of the residency will be implemented.

Producing a physician workforce committed to addressing SDH and health equity relies heavily on a workforce that can sustain working in underserved communities, an area that has been difficult to attract and maintain a physician workforce and suffers from high physician burnout. Prior study suggests that family medicine physicians working in urban underserved settings are sustained in this setting by their sense of identity and purpose. ${ }^{30}$ This sentiment was mirrored by our community partners, who expressed that they found purpose and meaning teaching the residents to identify $\mathrm{SDH}$ and the effects of SDH on health equity and thereby provide better care to a community and feel empowered to develop solutions to the problems they witness.

\section{Limitations}

The limitations of the CHAMP evaluation are associated with the number of resident cohorts who have completed the full curriculum. The phasedin rollout of the curriculum combined with changes of program leadership/new faculty hires limited our ability to compare outcomes from classes prior to full CHAMP implementation. While the evaluation design obtained inputs from multiple stakeholders, the data is primarily self-reported perceptions. Long term, we will seek Kirkpatrick level 4 results to evaluate CHAMP's effects on residency practice, as associating CHAMP with impacts on the health care system and southeastern Wisconsin will be difficult to obtain. As residents graduate from our program, we will have the opportunity for those hired into the Aurora Health Care system to track impact compared to non-Aurora trained physicians.

\section{CONCLUSIONS}

Published reports of GME programs explicitly designed to prepare residents to address health disparities and social determinants of health are needed. This assessment of the Aurora Family Medicine Residency CHAMP curriculum provides early outcomes, including community partner feedback, of an example curriculum that a) spans all 3 years of residency; b) combines block mandatory rotations with longitudinal elective experience; and c) integrates community health, advocacy, and managing populations.

Future efforts to refine the curriculum based on feedback from learners, faculty, program leadership, program administrator, and community partners are needed to continue to adapt the curriculum to increase translational learning and long-term outcomes to address social determinants of health and increase health equity.

\section{Patient-Friendly Recap}

- Physicians must be able to identify social determinants of health to address health disparities but often lack appropriate training.

- Community Health, Advocacy, and Managing Populations (CHAMP) is a residency curriculum that trains family physicians to identify and address social determinants of health and health disparities.

- Faculty and community partners valued teaching and mentoring young physicians in this innnovative training program and noted related changes in subsequent patient care. 


\section{Author Contributions}

Study design: Knox, Lehmann, Simpson. Data acquisition and analysis: all authors. Manuscript drafting: all authors. Critical revision: all authors.

\section{Conflicts of Interest}

None.

\section{References}

1. Berwick DM, Nolan TW, Whittington J. The triple aim: care, health, and cost. Health Aff (Millwood). 2008;27:759-69. CrossRef

2. Committee on Integrating Primary Care and Public Health; Board on Population Health and Public Health Practice; Institute of Medicine. Primary Care and Public Health: Exploring Integration to Improve Population Health. Washington, DC: National Academies Press, 2012, p. 4. CrossRef

3. Institute of Medicine (US) Committee on Educating Public Health Professionals for the 21st Century; Gebbie K, Rosenstock L, Hernandez LM (eds). Who Will Keep the Public Healthy? Educating Public Health Professionals for the 21st Century. Washington, DC: National Academies Press, 2003, pp. 5-7. CrossRef

4. Goldman LR, Kumanyika SK, Shah NR. Putting the health of communities and populations first. JAMA. 2016;316:1649-50. CrossRef

5. World Health Organization. Social determinants of health. http://www.who.int/social_determinants/sdh_definition/en/. Accessed June 18, 2017.

6. Marmot M. Social determinants of health inequalities. Lancet. 2005;365:1099-104.

7. Greer DM, Baumgardner DJ, Bridgewater FD, et al. Milwaukee Health Report 2013: Health Disparities in Milwaukee by Socioeconomic Status. Milwaukee, WI: Center for Urban Population Health, 2013.

8. Committee on Educating Health Professionals to Address the Social Determinants of Health; Board on Global Health; Institute of Medicine; National Academies of Sciences, Engineering, and Medicine. A Framework for Educating Health Professionals to Address the Social Determinants of Health. Washington, DC: National Academies Press, 2016, pp. 1-2. CrossRef

9. Accreditation Council for Graduate Medical Education. ACGME program requirements for graduate medical education in family medicine. Revised June 2017. http://www. acgme.org/Portals/0/PFAssets/ProgramRequirements/120_ family_medicine_2017-07-01.pdf. Accessed July 11, 2017.

10. Wieland ML, Beckman TJ, Cha SS, Beebe TJ, McDonald FS; Underserved Care Curriculum Collaborative. Resident physicians' knowledge of underserved patients: a multiinstitutional survey. Mayo Clin Proc. 2010;85:728-33. CrossRef

11. Ferguson WJ, Cashman SB, Savageau JA, Lasser DH. Family medicine residency characteristics associated with practice in a health professions shortage area. Fam Med. 2009;41:405-10.

12. Girotti JA, Loy GL, Michel JL, Henderson VA. The Urban Medicine Program: developing physician-leaders to serve underserved urban communities. AcadMed. 2015;90:1658-66. $\underline{\text { CrossRef }}$
13. Bachofer S, Velarde L, Clithero A. Laying the foundation: a residency curriculum that supports informed advocacy by family physicians. Am J Prev Med. 2011;41(4 Suppl 3): S312-3. CrossRef

14. Hasnain M, Massengale L, Dykens A, Figueroa E. Health disparities training in residency programs in the United States. Fam Med. 2014;46:186-91.

15. United States Census Bureau. QuickFacts: Milwaukee city, Wisconsin. https://www.census.gov/quickfacts/fact/table/ milwaukeecitywisconsin/PST045216. Accessed July 6, 2017.

16. Kaprielian VS, Silberberg M, McDonald MA, et al. Teaching population health: a competency map approach to education. Acad Med. 2013;88:626-37. CrossRef

17. Haq C, Stearns M, Brill J, et al. Training in Urban Medicine and Public Health: TRIUMPH. Acad Med. 2013;88:352-63. CrossRef

18. Brill JR, Ohly S, Stearns MA. Training communityresponsive physicians. (abstr.) Acad Med. 2002;77(7):747. CrossRef

19. Furin J, Farmer P, Wolf M, et al. A novel training model to address health problems in poor and underserved populations. J Health Care Poor Underserved. 2006;17:17-24. CrossRef

20. Accreditation Council on Graduate Medical Education; American Board of Family Medicine. The Family Medicine Milestone Project. October 2015. https://www.acgme.org/ Portals/0/PDFs/Milestones/FamilyMedicineMilestones.pdf. Accessed July 6, 2017.

21. Kretzmann JP, McKnight JL. Building Communities From the Inside Out: A Path Toward Finding and Mobilizing a Community's Assets. Skokie, IL: ACTA Publications, 1993.

22. Romain A. The patient in context: teaching core psychosocial assessment skills through the use of ecomaps. Sparrow/ Michigan State University Family Medicine Residency Program; shared with permission through the Society of Teachers of Family Medicine Resource Library. https:// resourcelibrary.stfm.org/resourcelibrary/viewdocument/thepatient-in-context-teaching-co. Accessed October 1, 2016.

23. Behforouz HL, Drain PK, Rhatigan JJ. Rethinking the social history. N Engl J Med. 2014;371:1277-9. CrossRef

24. Swain GR, Grande KM, Hood CM, Inzeo PT. Health care professionals: opportunities to address social determinants of health. WMJ. 2014;113:218-22.

25. Kirkpatrick JD, Kirkpatrick WK. Kirkpatrick's Four Levels of Training Evaluation. Alexandria, VA: ATD Press, 2016.

26. Teherani A, Martimianakis T, Stenfors-Hayes T, Wadhwa A, Varpio L. Choosing a qualitative research approach. J Grad Med Educ. 2015;7:669-70. CrossRef

27. Balmer DF, Rama JA, Athina Tina Martimianakis M, Stenfors-Hayes T. Using data from program evaluations for qualitative research. $J$ Grad Med Educ. 2016;8:773-4. CrossRef

28. Cho JY, Lee EH. Reducing confusion about grounded theory and qualitative content analysis: similarities and differences. The Qualitative Report. 2014;19(32):1-20.

29. Yoder KM. A framework for service-learning in dental education. J Dent Educ. 2006;70:115-23.

30. Getzin A, Bobot BL, Simpson D. Sustaining family physicians in urban underserved settings. Fam Med. 2016;48:809-13.

(C) 2018 Aurora Health Care, Inc. 